This is a post-peer-review, pre-copyedit version of an article published in the Journal of the Operational Research Society. The definitive publisher-authenticated versionWaterson, B.J., Hounsell, N.B. and Chatterjee, K. (2001) Quantifying the potential savings in travel time resulting from parking guidance systems - a simulation case study. Journal of the Operational Research Society, 52, (10), 1067-1077. (doi:10.1057/palgrave.jors.2601207) - is available online at:

http://www.palgrave-journals.com/jors/journal/v52/n10/abs/2601207a.html

\title{
Quantifying the potential savings in travel time resulting from parking guidance systems - a simulation case study
}

\author{
B.J. Waterson,* N.B. Hounsell and K. Chatterjee \\ Transportation Research Group, University of Southampton
}

\begin{abstract}
Parking Guidance and Information (PGI) signs are thought to enable a more efficient use of the available parking stock. Despite the installation of PGI systems in many cities and their operation for a number of years, there is a lack of reliable evidence of the size of the benefits that these systems can achieve. This paper describes the development of driver parking choice models (both during the journey and pre-trip) and the implementation of these models in the existing network traffic simulation model RGCONTRAM. Besides quantifying the effects of the PGI system on both the drivers seeking suitable parking spaces and the parking stock itself, this also enables quantification of the impact of parking choice on the wider network. Factors influencing PGI effectiveness are described and conclusions are drawn that illustrate the potential of PGI to induce the demand to spread more efficiently across the parking stock.
\end{abstract}

Keywords: Vehicle Routing, Car Parking, Traffic Assignment, Driver Information, Simulation

\section{Introduction}

As car ownership levels and use continue to rise, finding a parking space in city-centre car parks can be an increasing problem for motorists. The time spent driving between different car parks or queuing at the entrances creates both an economic cost (wasted time) and an environmental cost (increased levels of exhaust pollution). In many cities, small groups of car parks are extremely popular and fill very early in the day. This leads to long queues at the car park entrance barriers, which often prevent vehicles from entering the car park until another vehicle departs and a parking space becomes available. Other car parks in the same city-centres, which may have entrances close to the popular car parks, may be under utilised however, with spaces frequently being available throughout the day and therefore few queues developing at the entrance barriers. This uneven 'assignment' of vehicles to car parks suggests that savings in travel time may be achievable if vehicles travelled directly to a suitable car park.

The choice of car park in which a driver attempts to park and the route which they take to reach it are the outcomes of highly complex decision processes. An important means by which these choices can be influenced is through providing drivers with information, thereby helping them to choose a car park where there are spaces rather than a car park that is full to capacity. This type of parking guidance information (PGI) is usually conveyed to drivers by means of roadside displays (PGI signs), such as those in Figure 1.

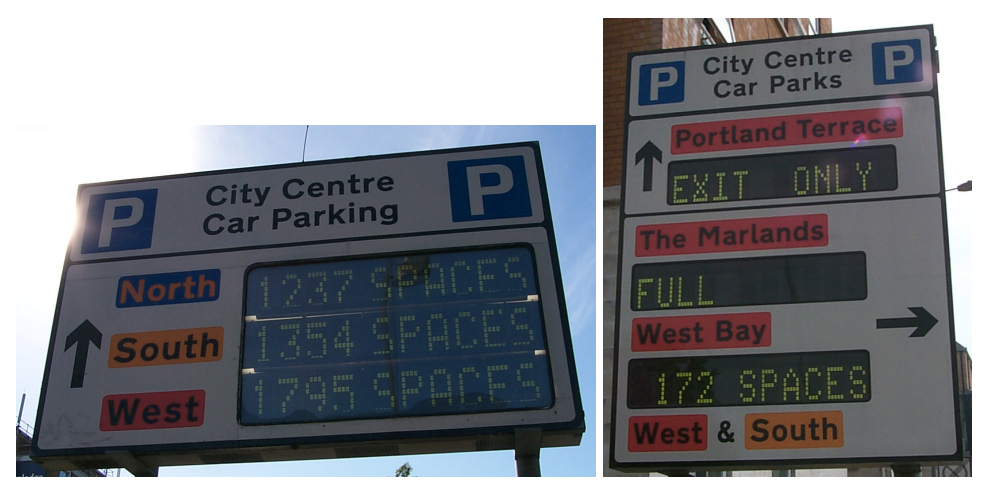

Figure 1 Examples of PGI signs (Southampton)

Although such PGI systems have been installed in many cities around the world, there is little knowledge as to their effect on overall journey time and the relative effectiveness of different PGI system formats. Often the installation takes place as part of an ongoing programme of development and restructuring of car parking facilities in the city as a whole, leading to difficulties in carrying out before-and-after studies to isolate the effects of the PGI system. Tentative studies, ${ }^{1-5}$ have identified that drivers do change car parks following the installation of a PGI system, although estimates of the overall effects of these changes are varied.

This paper reports on elements of a collaborative study by researchers at three English universities (Southampton, Leeds and Imperial College, London) to develop a model of driver parking choice and thereby quantify the potential savings in travel time that PGI systems can achieve. The characteristics of the problem to be solved are examined and the data requirements summarised, before an overview of the behavioural models developed during the study 
This is a post-peer-review, pre-copyedit version of an article published in the Journal of the Operational Research Society. The definitive publisher-authenticated versionWaterson, B.J., Hounsell, N.B. and Chatterjee, K. (2001) Quantifying the potential savings in travel time resulting from parking guidance systems - a simulation case study. Journal of the Operational Research Society, 52, (10), 1067-1077. (doi:10.1057/palgrave.jors.2601207) - is available online at:

http://www.palgrave-journals.com/jors/journal/v52/n10/abs/2601207a.html

and the simulation methodology followed is given. These results were originally presented ${ }^{6}$ at the $41^{\text {st }}$ annual conference of the Operational Research Society in Edinburgh, 1999.

\section{Queuing Model}

To identify the specific characteristics and problems of modelling car park choice, consider first a line of checkouts in a large supermarket. From the point of view of an individual shopper, the optimum scenario is that they can walk straight up to a checkout and pay for their purchases without having to queue at all. This is rarely possible at busy times however, as shoppers who are waiting in the queue at one checkout can see both the lengths of queues at all the other checkouts and the rates at which they are moving. If these shoppers decide, based on these rates, that changing to an alternative queue would mean that their queuing time would reduce, then they will change (often referred to as jockeying in queuing theory). In reality, the queuing process at a line of checkouts is not quite that simple, but essentially the same process occurs at car park entrances. The difference is that in the supermarket the ability to see all the other queues leads to a distribution of shoppers among checkouts closer to optimum. At car park entrances, the drivers in the queues cannot (normally) see the other car park entrances and corresponding queues, so jockeying cannot occur without drivers being provided with this information.

By definition, for queues at both supermarket checkouts and car park entrances, the optimum solution is that leading to the lowest average queuing time across all shoppers or vehicles. This must be achieved within the physical constraint of the number of servers in the system (checkouts or car parks). Note that this optimum solution does not necessarily correspond to the optimum solution for each individual in the system, which is to experience zero queuing time.

There are two differences between the supermarket checkouts and the car parks that prevent us from obtaining algebraic solutions for the optimum queuing time in the same way. Firstly, a supermarket checkout can only serve one (or possibly two) shopper(s) at once and the service time is determined by the speed of the operator (leading to shoppers with identical baskets of goods potentially experiencing different service times at different checkouts). A car park, in contrast, can service many vehicles simultaneously and it is the motorist, rather than the car park, who determines the service time (length of stay), except where different pricing structures induce different choices in parking duration. The second reason is apparent when the different stages in the journey of an individual car driver from origin to final destination are considered:

(i) 'Driving' to the car park.

(ii) 'Queuing' at the car park entrance.

(iii) 'Searching' for a space inside the car park.

(iv) 'Walking' from parked car to final destination.

Whereas a queuing model can encompass all these stages for a single individual, it cannot account for the interactions among vehicles driving between car parks or the effect that large queues frequently have on traffic passing by the car park entrances. This circulating and queuing traffic increases the travel times of the other vehicles in the network. The equivalent scenario in the supermarket is the queues of shoppers at the checkouts stretching back so far that they (and other shoppers trying to find a suitable checkout) prevent other shoppers from moving freely about the store. To capture this consequence of the car park choice process a simulation model is required.

\section{Sources of Data}

The data necessary to model the parking choice process can be classified into physical and behavioural data.

(i) Physical data is the information about the road network layout, normal traffic levels, car park capacities and car park entrance barriers required to enable the simulation to be based in a realistic environment. Information from the city of Southampton (UK) was used to create the simulation environment in this study. As a PGI system already operates in Southampton, a central computer collects information on car park occupancy levels. This information, along with traffic flows collected by a $\mathrm{SCOOT}^{7}$ traffic control system, enabled validation of the simulation model and simulated environment.

(ii) Behavioural data is information about how drivers respond when faced with certain stimuli, such as different car park conditions or parking guidance information. To determine the factors which people considered when selecting a car park, data from questionnaire surveys of car park users carried out in Southampton as part of the EUROSCOPE project $^{8}$ was analysed. Table 1 shows the factors most frequently identified by those interviewed, illustrating a clear split between (i) those drivers for whom this was their first visit to the city and (ii) those drivers who were more familiar with the networks. The unfamiliar drivers appeared to place much greater emphasis on road signs and 
This is a post-peer-review, pre-copyedit version of an article published in the Journal of the Operational Research Society. The definitive publisher-authenticated versionWaterson, B.J., Hounsell, N.B. and Chatterjee, K. (2001) Quantifying the potential savings in travel time resulting from parking guidance systems - a simulation case study. Journal of the Operational Research Society, 52, (10), 1067-1077. (doi:10.1057/palgrave.jors.2601207) - is available online at:

http://www.palgrave-journals.com/jors/journal/v52/n10/abs/2601207a.html

information and less on the proximity of the car park to their destination. This suggested that familiar and unfamiliar drivers needed to be considered as separate cases in the simulation model, with a third group of drivers (those using private, non-residential (PNR) parking) having a fixed parking space.

\begin{tabular}{|c|c|c|c|c|c|c|c|}
\hline & \multicolumn{6}{|c|}{ Frequency of Visits to City } & \multirow[b]{2}{*}{ Overall } \\
\hline & First visit & $\begin{array}{l}<\text { Once } \\
\text { per Year }\end{array}$ & $\begin{array}{c}\text { Once per } \\
\text { Month }\end{array}$ & $\begin{array}{l}\text { Once per } \\
\text { Fortnight }\end{array}$ & $\begin{array}{c}\text { Once per } \\
\text { Week }\end{array}$ & $\begin{array}{c}>\text { Once } \\
\text { per Week }\end{array}$ & \\
\hline Proximity & $31 \%$ & $74 \%$ & $71 \%$ & $67 \%$ & $69 \%$ & $86 \%$ & $71 \%$ \\
\hline Easy Drive & $13 \%$ & $4 \%$ & $14 \%$ & $7 \%$ & $16 \%$ & $3 \%$ & $9 \%$ \\
\hline Spare Spaces & $9 \%$ & $7 \%$ & $11 \%$ & $15 \%$ & $6 \%$ & $1 \%$ & $8 \%$ \\
\hline Road Signs & $34 \%$ & $7 \%$ & $0 \%$ & $1 \%$ & $1 \%$ & $0 \%$ & $3 \%$ \\
\hline Cost & $0 \%$ & $0 \%$ & $0 \%$ & $1 \%$ & $6 \%$ & $4 \%$ & $2 \%$ \\
\hline Security & $3 \%$ & $0 \%$ & $2 \%$ & $1 \%$ & $1 \%$ & $1 \%$ & $1 \%$ \\
\hline Other & $9 \%$ & $7 \%$ & $3 \%$ & $8 \%$ & $2 \%$ & $5 \%$ & $6 \%$ \\
\hline Total & $100 \%$ & $100 \%$ & $100 \%$ & $100 \%$ & $100 \%$ & $100 \%$ & $100 \%$ \\
\hline
\end{tabular}

Table 1 Reasons Identified in Choice of Car Park

\section{Parking Choice Models}

Once the important factors in car park choice had been identified, a driver simulator could be developed to estimate these factors and to assess driver behaviour in the face of different car park conditions and parking guidance information under controlled conditions. The driver simulator developed in this study was PARKIT ${ }^{9}$, a computer programme designed to guide drivers through a series of simulated journeys, requiring them to choose route and car parks, and providing feedback via a simulated dashboard and view from the driving seat. Throughout the experiment all responses are logged, enabling the response to different scenarios and amounts of parking guidance information to be examined.

To model all the aspects of the behaviour exhibited by the participants in the experiment, drivers in the simulation model were identified as being in one of the three groups (familiar, unfamiliar or PNR) and parking choice models developed as shown in Table 2 where "_. indicates that no explicit car park choice is made by drivers in that group at that point in their journey. More detail on the derivation and calibration of the models described here can be found in the paper by Bonsall and Palmer. ${ }^{10}$

\begin{tabular}{|c|c|c|c|}
\hline Type of Driver & Choice at Origin & Choice En-Route & Choice at Car-Park Entrance \\
\hline Familiar & {$[\mathrm{A}]-$ Initial Choice } & \multicolumn{2}{|c|}{$[\mathrm{B}]-$ Exit Choice } \\
\hline Unfamiliar & - & {$[\mathrm{D}]$ - Revised Choice } & {$[\mathrm{C}]$ - Stopping Model } \\
\hline PNR & - & - & - \\
\hline
\end{tabular}

Table 2 Parking Choice Models

\section{- [A] - Familiar Drivers' Initial Choice of Car Park}

The surveys of car park users (carried out to identify the significant factors in car park choice) indicated that approximately $80 \%$ of the drivers interviewed who had visited the city before had selected an initial choice of car park, in which to try and park, before reaching the city centre. PARKIT was used to develop the following multinomial logit model for initial car park choice (see equations (1) and (2)), which was designed to capture this aspect of parking behaviour.

$U_{i}=\left(0.49 E_{i}+1.24 L_{i}\right)-\left(0.08 W_{i}+0.005 C_{i}\right)$

Where....

$U_{i} \quad$ is the utility of car park $i$

$E_{i} \quad$ is 1 if the expected chance of having to queue for more than five minutes outside car park $i$ is less than $5 \%$; 0 otherwise

$L_{i} \quad$ is 1 if car park $i$ was the last car park used by the driver, 0 otherwise

$W_{i} \quad$ is the walking time (in minutes) from car park $i$ to the final destination

$C_{i} \quad$ is the cost (in pence) of parking in car park $i$.

Moreover, the assumption is that each driver knows all this information, as they are familiar with both the car parks and their usual occupancy levels. 
This is a post-peer-review, pre-copyedit version of an article published in the Journal of the Operational Research Society. The definitive publisher-authenticated versionWaterson, B.J., Hounsell, N.B. and Chatterjee, K. (2001) Quantifying the potential savings in travel time resulting from parking guidance systems - a simulation case study. Journal of the Operational Research Society, 52, (10), 1067-1077. (doi:10.1057/palgrave.jors.2601207) - is available online at:

http://www.palgrave-journals.com/jors/journal/v52/n10/abs/2601207a.html

The terms in (1) mainly reflect the results shown in Table 1 , although a further term $\left(L_{i}\right)$ arose in the calibration of this model from the PARKIT data. $L_{i}$ is an inertia term, representing the tendency of drivers to return to the last car park that they used. The form of (1) suggests that drivers are performing a trade off between the attractiveness of each car park (low chance of having to queue for over five minutes) and the corresponding disadvantages (distance from final destination and monetary cost).

When the utility of each car park has been calculated by (1), the probability of the driver initially choosing each car park $i$ is $P_{i}$ calculated using the multinomial logit model (2), where $j$ represents all car parks in the network. The initial choice for the individual driver is then produced via a Monte-Carlo simulation methodology.

$P_{i}=\mathrm{e}^{U_{i}} / \sum_{j} \mathrm{e}^{U} j$

\section{- [B] - Familiar Drivers' Choice of Exit En-Route}

Although familiar drivers initially select a car park, they may change their route or car park choice after their journey has begun due to congestion, the queue passed at a car park entrance or information received. This aspect of parking behaviour is modelled by allowing drivers to select the exit from each junction as their journey is simulated, rather than choose explicitly between car parks. Firstly, the utility of each possible car park is calculated by equation (3), and then the utility of each exit from the current junction is calculated using the hierarchical multinomial logit model (4).

$$
\begin{aligned}
U_{i}=\left(2.35 N_{i}-\right. & \left.0.004 C_{i}-0.36 D_{i}-0.10 W_{i}\right) \\
& +\left(1.32 A_{i}-1.74 R_{i}-0.63 V_{i}\right) \\
& +\left(0.04 \min \left(S_{i}, 50\right)-0.0001 \min \left(S_{i}, 50\right)^{2}-0.77 F_{i}\right)
\end{aligned}
$$

Where....

$U_{i} \quad$ is the utility of car park $i$

$N_{i} \quad$ is 1 if car park $i$ was the initially intended car park chosen by (1) above, 0 otherwise

$C_{i} \quad$ is the cost (in pence) of parking in car park $i$

$D_{i} \quad$ is the expected drive time (in minutes) to reach car park $i$ from the current junction

$W_{i} \quad$ is the walking time (in minutes) from car park $i$ to the destination

$A_{i} \quad$ is 1 if the current junction is at the entrance of car park $i, 0$ otherwise

$R_{i} \quad$ is 1 if car park $i$ has already been passed and rejected, 0 otherwise

$V_{i} \quad$ is the visible wait (in minutes) if outside car park $i, 0$ otherwise

$S_{i} \quad$ is the most recent number of spaces for car park $i$ given on a PGI sign, 0 if 'FULL' or a historical value (representing the driver having knowledge of the normal level of spaces) if no PGI signs have been passed

$F_{i} \quad$ is 1 if the most recent parking guidance information about car park $i$ was that it was 'FULL', 0 otherwise or if no PGI signs have been passed.

The terms involving $S_{i}$ indicate that drivers interpret any number of available spaces above fifty in the same way, i.e. this is the value at which they feel they are certain to be able to find a space and therefore higher values have no additional influence on the decision. The effect of the number of available spaces information is also non-linear, with the marginal effects reducing as the value approaches fifty.

Note that the factors considered by the driver represent almost all those identified in Table 1. Further, the form of the model suggests that the factors can be split into three groups. Normal conditions $\left(N_{i}, C_{i}, D_{i}, W_{i}\right)$, current conditions $\left(A_{i}, R_{i}, V_{i}\right)$ and expected conditions $\left(S_{i}, F_{i}\right)$. The signs of the coefficients again indicate that a trade off is taking place between the attractiveness of each car park and its corresponding disadvantages.

$U E_{j}=\left\{\begin{array}{l}0 \text { if no car parks are assigned to exit } j \\ U_{i} \text { if only car park } i \text { is assigned to exit } j \\ 0.73 \ln \sum_{i} \mathrm{e}_{i} \text { otherwise. }\end{array}\right.$ 
This is a post-peer-review, pre-copyedit version of an article published in the Journal of the Operational Research Society. The definitive publisher-authenticated versionWaterson, B.J., Hounsell, N.B. and Chatterjee, K. (2001) Quantifying the potential savings in travel time resulting from parking guidance systems - a simulation case study. Journal of the Operational Research Society, 52, (10), 1067-1077. (doi:10.1057/palgrave.jors.2601207) - is available online at:

http://www.palgrave-journals.com/jors/journal/v52/n10/abs/2601207a.html

Where $U E_{j}$ is the utility of exit $j, U_{i}$ is the utility of car park $i$ computed from (3) and car parks are assigned to the exit which leads to the shortest drive time to the car park under normal congestion conditions. The summation is over all car parks $\mathrm{i}$ that are assigned to exit $\mathrm{j}$ and the actual choice for the individual driver is then produced via multinomial logit model probabilities using (2) and Monte-Carlo simulation.

When the driver selects a parking access link (see Figure 2) as the preferred exit, then they join the (possibly zero length) queue for that car park. If a parking access link is one of the available exits from the current junction and is not selected, then the driver is marked as having rejected that car park. Because of the form of the model (exit choice rather than explicit car park choice), the precise reason for rejecting the car park is not known. A rejected car park is still considered in future exit choices and a driver returning to a previously rejected car park would be deemed to have failed to find a more suitable car park and is not normally allowed to reject the same car park again.

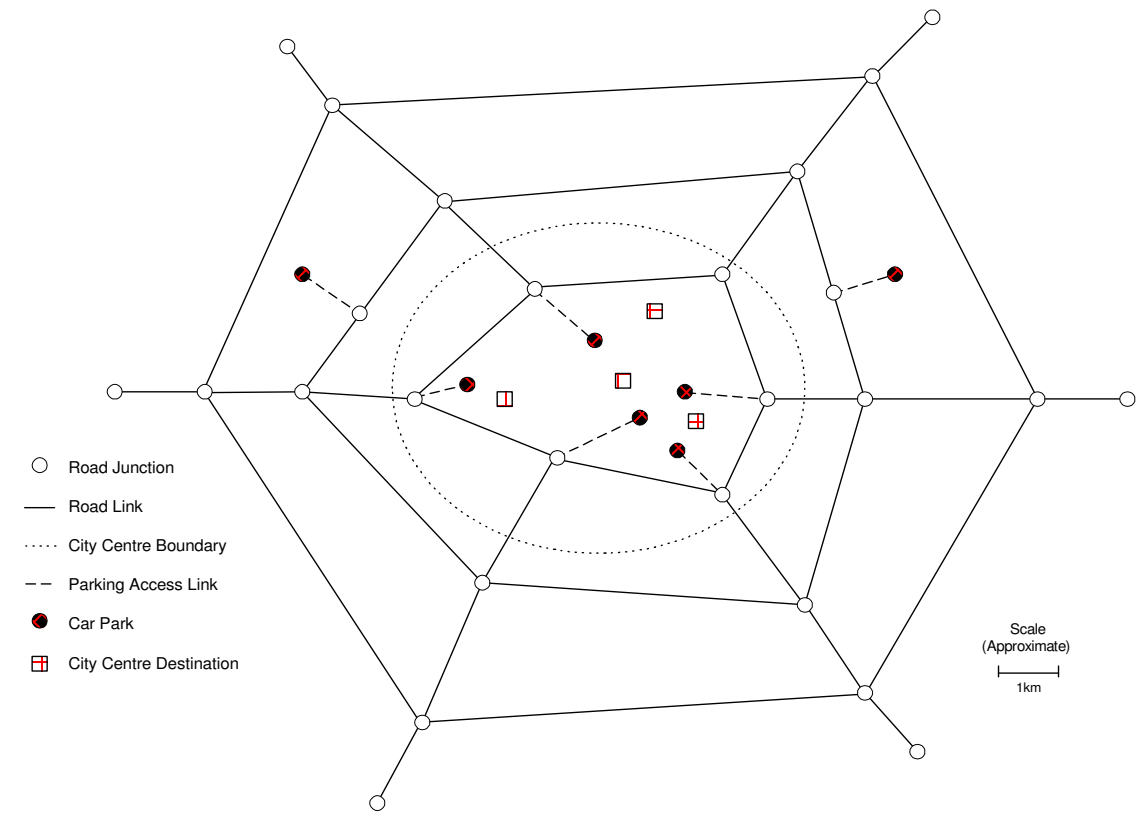

Figure 2 Simulated Road and Car Park Network

\section{- [C] - Unfamiliar Drivers' Stopping Model}

Drivers who are unfamiliar with the network are assumed in the model to have little knowledge about normal levels of traffic congestion and car park occupancies. Therefore, unlike drivers who are more familiar with the network, they are not assigned an initial choice of car park, but instead drive directly towards their destination. At each car park entrance passed on their journey they make a choice between queuing at that car park or continuing on their journey in search of a 'better' car park, with the choice made according to the following stopping model.

$$
U_{\text {park }}=0.43 \ln \sum_{i} \mathrm{e}^{-\left(0.01 C_{i}+1.04 Q_{i}\right)}
$$

Where....

$C_{i}$ is the cost (in pence) of parking at car park $i$

$Q_{i} \quad$ is the estimated current queuing time (in minutes) outside car park $i$.

.....and the summation is across all car parks at the current junction.

$P_{\text {park }}=\mathrm{e}^{U \text { park }} /\left(\mathrm{e}^{-3.8}+\mathrm{e}^{U}\right.$ park $)$

Where $P_{\text {park }}$ is the probability that the driver will choose to park and the actual choice is made in the model by Monte-Carlo simulation. The $\mathrm{e}^{-3.8}$ term represents the (comparative) utility of continuing on the journey and the cost term (which is itself a function of desired duration of stay) and is necessary to enable drivers to distinguish between long-stay and short-stay car parks. 
This is a post-peer-review, pre-copyedit version of an article published in the Journal of the Operational Research Society. The definitive publisher-authenticated versionWaterson, B.J., Hounsell, N.B. and Chatterjee, K. (2001) Quantifying the potential savings in travel time resulting from parking guidance systems - a simulation case study. Journal of the Operational Research Society, 52, (10), 1067-1077. (doi:10.1057/palgrave.jors.2601207) - is available online at:

http://www.palgrave-journals.com/jors/journal/v52/n10/abs/2601207a.html

If unfamiliar drivers reach the vicinity of their destination without having chosen to park at a car park, then they circle within the local area attempting to find a suitable car park and applying the stopping model (in (5) and (6)) at each car park entrance they pass.

\section{- [D] - Unfamiliar Drivers' Revised Car Park Choice}

Unfamiliar drivers are not initially assigned an intended car park, but if they pass a PGI sign providing information that a car park close to their destination has available spaces, then this car park becomes their primary choice. Information on car parks closer to their destination from subsequent PGI signs may alter this choice, but the stopping model is still applied at each car park entrance that they pass.

\section{Network Simulation Methodology}

To assess the effects of individual driver behaviour (relating to choice of both car park and route) on the travel times of all the motorists in the network, the parking choice models above were incorporated into the existing network traffic simulation model RGCONTRAM ${ }^{11}$. This model is based on CONTRAM (CONtinuous TRaffic Assignment Model $)^{12}$, a model that enables the simulation of traffic levels across a whole network, including the effects of traffic congestion and queues that block across junctions. RGCONTRAM however models single day traffic assignments which are necessary to represent drivers reactions to PGI, rather than equilibrium assignments. ${ }^{13}$

RGCONTRAM was originally developed to examine the benefits of making dynamic route guidance information available to a proportion of drivers following unexpected incidents within the network, such as accidents or emergency roadworks. Within this study, RGCONTRAM provided the capability to model unexpected events such as car park occupancy levels being different to normal, thus enabling the effectiveness of PGI signs to be examined under different scenarios.

The network simulated in this study was based on the city of Southampton in terms of overall scale, road layout and car parking facilities, but adjusted to remove those characteristics peculiar to the city. The network was then simplified to enable results to be more easily interpreted and generalised. Figure 2 shows a map of the final network layout, in which forty thousand vehicle journeys were modelled during each simulation run.

Although the 'Driving' section of the route of each vehicle in the network is modelled within RGCONTRAM, the other three sections of the route ('Queuing', 'Searching' and 'Walking') needed to be included in the model. Reducing the rate at which vehicles on the parking access links were allowed to enter the car park as occupancy reached capacity produced queues at car park entrances. This was designed to mimic the effect of entrance barriers preventing access to the car park when there was no spare capacity.

Searching time within the car park however could not be explicitly modelled without a large amount of research into traffic flow patterns within a car park. Therefore (7), a relationship between car park occupancy and searching time derived from surveys of car park users in London ${ }^{14}$, was used to estimate the searching time based on the current car park occupancy level. This relationship produces searching times as shown in Figure 3.

$S T m=\left\{\begin{array}{cc}\alpha /(1-\text { Occ } / \text { Cap }) & \text { Occ }<\rho \text { Cap } \\ \alpha(1+\text { Occ } / \text { Cap }-2 \rho) /(1-\rho)^{2} & \text { Occ } \geq \rho \text { Cap }\end{array}\right.$

Where....

STm is the estimated search time (in minutes).

Cap is the capacity of the car park.

Occ is the current occupancy of the car park.

$\rho=0.9$ and $\alpha=0.47$ were estimated from survey data. 
This is a post-peer-review, pre-copyedit version of an article published in the Journal of the Operational Research Society. The definitive publisher-authenticated versionWaterson, B.J., Hounsell, N.B. and Chatterjee, K. (2001) Quantifying the potential savings in travel time resulting from parking guidance systems - a simulation case study. Journal of the Operational Research Society, 52, (10), 1067-1077. (doi:10.1057/palgrave.jors.2601207) - is available online at: http://www.palgrave-journals.com/jors/journal/v52/n10/abs/2601207a.html

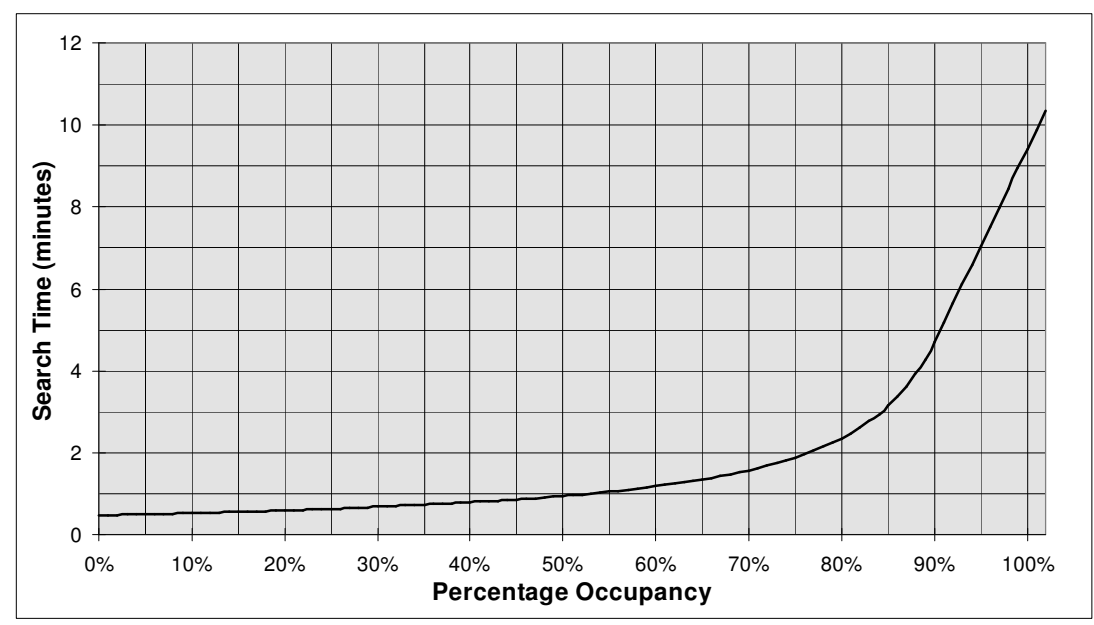

Figure 3 Estimated Search Times

The need to include the walking section of the route within the model gave rise to two issues. Firstly, a maximum permitted walking distance was required to prevent drivers considering car parks far away from their destination. The second issue concerns the traditional method of economic assessment of transport projects ${ }^{15}$, which places twice the value on out-of-vehicle time (for example walking or waiting at a bus-stop) that is placed on in-vehicle time. The implication of these different values of time in this study where walking is an integral part of the journey is that a policy that decreases driving, queuing or searching time, but increases walking time by the same amount would be adjudged to have increased the total travel cost even though the total travel time would have remained unchanged. To prevent this misinterpretation of total travel cost, all calculations were performed using the same value of time for all four sections of the journey.

Before attempting to quantify the potential travel times savings that PGI systems can achieve under different network conditions, the validity of the simulated results needed to be established. This was achieved by comparing them against known car park occupancies from the Southampton network (appropriately adjusted for the changes made to the network) and against the behavioural data collected using the PARKIT simulator. Specific indicators included the simulated car park occupancy levels and the proportion of familiar drivers parking in their initial choice of car park. The tests performed on the sensitivity of key results to small changes in the parking choice model coefficients, lead to slight alterations in the formulation of the models and therefore their coefficients. The final versions of the parking choice models are those given in equations (1) to (5) above.

\section{Experimental Design for Network Modelling}

The factors in the design that were thought potentially to affect the effectiveness of PGI signs in producing savings in travel times and which can be evaluated through network modelling were grouped into the following four areas.

\section{- Group 1 : PGI Signs}

(i) Sign Type

The parking choice models enabled three types of PGI sign to be simulated. 'Discrete' signs (which display either 'FULL' or 'SPACES' for each car park), 'Hybrid' signs (which display the number of available spaces when this is above a predetermined threshold and 'FULL' when below the threshold) and 'Hierarchical' signs (which display the total number of spaces in a group of car parks). Examples of a Hierarchical and a Hybrid PGI sign are shown in Figure 1.

\section{(ii) Sign Location}

PGI sign locations were selected to examine at which point, during their journey, it was most beneficial to provide drivers with information about space availability. The options compared were placing signs close to car park entrances (to provide drivers with information about alternative car parks when the current car park is full), placing signs at major decision points in the network far from the car park entrances (to direct drivers towards a suitable car park early in their journey) and an intensive coverage of PGI signs.

Combining (i) and (ii) produced eight PGI sign type and location strategies to be examined, ranging from no PGI signs (the base case strategy) to an intensive coverage of Hybrid and Hierarchical PGI signs. 
This is a post-peer-review, pre-copyedit version of an article published in the Journal of the Operational Research Society. The definitive publisher-authenticated versionWaterson, B.J., Hounsell, N.B. and Chatterjee, K. (2001) Quantifying the potential savings in travel time resulting from parking guidance systems - a simulation case study. Journal of the Operational Research Society, 52, (10), 1067-1077. (doi:10.1057/palgrave.jors.2601207) - is available online at:

http://www.palgrave-journals.com/jors/journal/v52/n10/abs/2601207a.html

- Group 2 : Network Design

(iii) Car park Size

Three car park size scenarios were simulated, each with the same total parking capacity. Many small car parks (a scenario designed to represent historic cities where off-street car parking is frequently split between many small sites), a few large car parks (a scenario designed to represent cities where off street parking is available at a small number of purpose built facilities) and a mixture of car park sizes.

(iv) Pricing Policy

Different pricing policies were designed to examine different levels of standardisation (both in cost and duration of stay periods) between car parks. 'Identical Pricing' where all car parks had exactly the same pricing structure (designed to represent all car parks being run by the same operator, effectively removing cost considerations from car park choice), 'Similar Pricing' where one pricing structure was applied to all city centre car parks, but out of centre car parks used a cheaper pricing structure and 'Different Pricing' where both costs and associated lengths of stay varied between individual car parks (designed to represent many different car park operators, each setting their own price structures).

- Group 3 : Parking Demand and Knowledge

(v) Proportion of Unfamiliar Drivers

Surveys of car park users during the project suggest that between 5\% and $10 \%$ of car park users are not familiar with the normal traffic conditions in the network and occupancy levels in the car parks. Two proportions of unfamiliar drivers in the network were selected to be compared, a normal value of $7 \%$ and the higher value of $14 \%$ which may be experienced (for example) if a special event is taking place in the city.

(vi) Demand Variation

Increasing the total number of vehicles attempting to use the car parks by increasing the total number of simulated vehicles in the network would be likely to produce an effect on the general level of congestion in the network which would obscure the effect on the car parks. This problem was overcome by representing higher levels of demand by reducing the total available parking capacity while keeping the total number of vehicles constant thus having an equivalent effect on the demand/supply ratio. Because of this alteration to supply rather than demand, caution must be taken when interpreting the magnitude of effects associated with this factor.

(vii) Awareness of PGI

Surveys during the project suggested that only $35 \%$ of familiar drivers and $55 \%$ of unfamiliar drivers utilised the information provided by PGI signs. These values and the effect of increasing either of these values to $75 \%$ (for example as the result of an advertising campaign) were compared.

- Group 4 : Unexpected Car Park Closure

(viii) It was thought that PGI signs might be at their most effective (in reducing travel times) when the capacity of a car parks in the network is suddenly reduced, for an example if a car park has to be partially closed. Note that this scenario is different to (vi) above, as here the drivers would not know about the closure before commencing their journey. Comparing normal and suddenly reduced capacities with and without PGI signs enables both the congestion caused by the car park closure to be quantified and the effectiveness of PGI in preventing this increase in congestion.

The final group of factors thought to influence the effectiveness of parking guidance information was the operation of the PGI signs (for example the capacity threshold below which the signs display 'FULL' or the frequency with which the information on the signs is updated). The limitations of the data collected using PARKIT did not allow the validity of the behavioural responses to be confirmed under any setting of these factors except normal operating procedures. Therefore this group of factors was omitted from the design.

The final experimental design consisted of three groups of scenarios. The first group were produced by a full factorial design, enabling estimation of the interactions among the PGI signs factors with the network design factors $(8 \times 3 \times 3=72$ factor combinations) with replicates provided by altering the initial seed values for the pseudo-random number sequences involved in the choice models. A similar full factorial design was then used for the interactions between the parking demand and knowledge factors with the PGI signs factors for the second group of scenarios and the unexpected car park closure factor with the PGI signs factors for the final group.

\section{Discussion of Results}

The results of each factor combination were examined by dividing the drivers into one of six groups depending on their type (familiar, unfamiliar or PNR drivers) and whether their journey passed a PGI sign or not. Table 3 provides 
This is a post-peer-review, pre-copyedit version of an article published in the Journal of the Operational Research Society. The definitive publisher-authenticated versionWaterson, B.J., Hounsell, N.B. and Chatterjee, K. (2001) Quantifying the potential savings in travel time resulting from parking guidance systems - a simulation case study. Journal of the Operational Research Society, 52, (10), 1067-1077. (doi:10.1057/palgrave.jors.2601207) - is available online at:

http://www.palgrave-journals.com/jors/journal/v52/n10/abs/2601207a.html

an example of the results produced for each scenario simulated. Care is needed in interpreting the results, as those drivers passing PGI signs tend to be those travelling longer distances and therefore driving times are proportionately higher.

\begin{tabular}{|c|c|c|c|c|c|c|c|c|}
\hline & & \multirow{2}{*}{\multicolumn{5}{|c|}{ Average Time (seconds) }} & \\
\hline & \multirow[b]{2}{*}{$\begin{array}{c}\text { Number } \\
\text { of } \\
\text { Drivers }\end{array}$} & & & & & & & \\
\hline & & Driving & Queuing & Searching & Walking & $\begin{array}{c}\text { Total } \\
\text { Journey }\end{array}$ & $\begin{array}{c}\text { Average } \\
\text { Distance } \\
\text { Driven } \\
(\mathrm{km})\end{array}$ & $\begin{array}{c}\text { Average } \\
\text { Number of } \\
\text { Car Parks } \\
\text { Rejected }\end{array}$ \\
\hline $\begin{array}{l}\text { PNR Drivers } \\
\text { Passing PGI }\end{array}$ & 15237 & 1371 & - & - & - & 1371 & 11.8 & - \\
\hline $\begin{array}{l}\text { PNR Drivers Not } \\
\text { Passing PGI }\end{array}$ & 10994 & 698 & - & - & - & 698 & 5.4 & - \\
\hline $\begin{array}{c}\text { Familiar Drivers } \\
\text { Passing PGI }\end{array}$ & 2997 & 1216 & 70 & 140 & 359 & 1785 & 8.9 & 0.65 \\
\hline $\begin{array}{l}\text { Familiar Drivers } \\
\text { Not Passing PGI }\end{array}$ & 7377 & 1119 & 74 & 140 & 367 & 1700 & 8.0 & 0.54 \\
\hline $\begin{array}{c}\text { Unfamiliar Drivers } \\
\text { Passing PGI }\end{array}$ & 275 & 1206 & 48 & 146 & 265 & 1665 & 9.1 & 0.87 \\
\hline $\begin{array}{c}\text { Unfamiliar Drivers } \\
\text { Not Passing PGI }\end{array}$ & 351 & 1042 & 36 & 136 & 319 & 1533 & 7.4 & 0.71 \\
\hline All Drivers & 37231 & 1106 & - & - & - & 1274 & 8.9 & - \\
\hline
\end{tabular}

Table 3 Example of Simulation Results

Figure 4 illustrates a way in which simulated percentage savings in average total travel time achieved by implementing different PGI sign type and location strategies can be compared. Each point on the graph indicates the saving achieved for the following seven PGI sign type and location strategies and different combinations of factors (i) to (vii) above.

1 Hybrid PGI Signs Close to Car Park Entrances.

3 Hybrid PGI Signs at Major Decision Points.

5 Intensive Coverage of Hybrid PGI Signs.

7 Intensive Coverage of Hybrid and Hierarchical PGI Signs.
2 Discrete PGI Signs Close to Car Park Entrances.

4 Discrete PGI Signs at Major Decision Points.

6 Intensive Coverage of Discrete PGI Signs.

In some scenarios simulated, Discrete PGI sign strategies produced increased average total travel times (negative savings), as drivers were only receiving limited information.

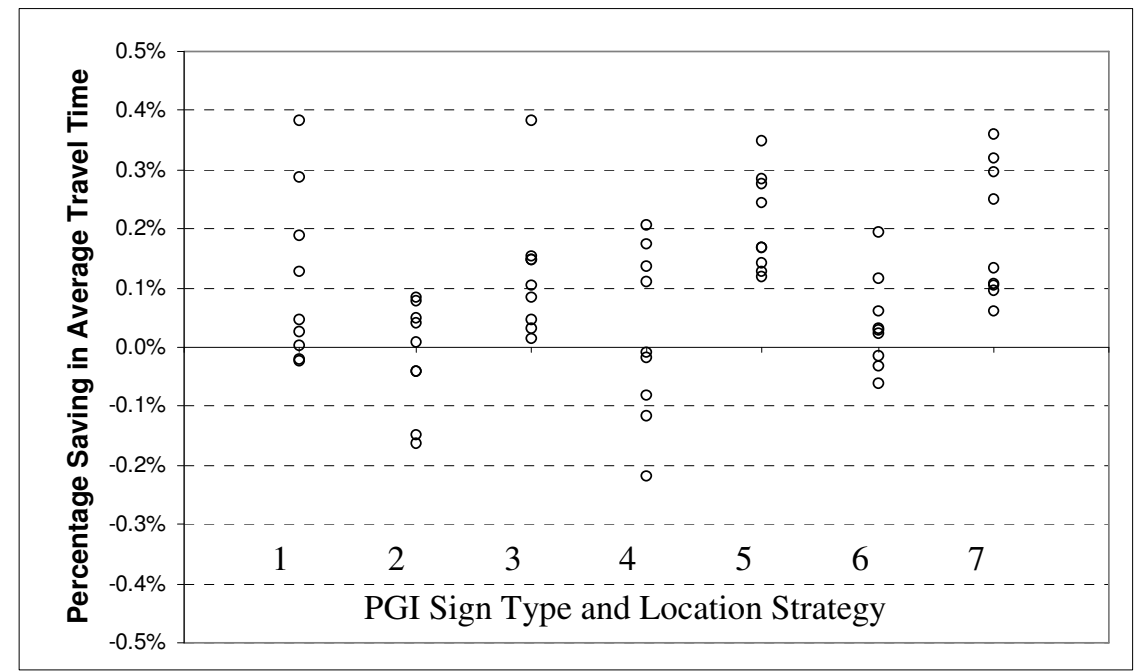

Figure 4 Example PGI Effectiveness

Figure 4 illustrates the general findings from the simulated scenarios, which suggest that Hybrid PGI signs are more effective in reducing average travel times than Discrete PGI signs at the same locations. One possible explanation may be that displaying the number of available spaces is more informative when a car park has only a few spaces 
This is a post-peer-review, pre-copyedit version of an article published in the Journal of the Operational Research Society. The definitive publisher-authenticated versionWaterson, B.J., Hounsell, N.B. and Chatterjee, K. (2001) Quantifying the potential savings in travel time resulting from parking guidance systems - a simulation case study. Journal of the Operational Research Society, 52, (10), 1067-1077. (doi:10.1057/palgrave.jors.2601207) - is available online at:

http://www.palgrave-journals.com/jors/journal/v52/n10/abs/2601207a.html

available, but sufficient for a discrete PGI sign still to indicate 'SPACES'. In this situation hybrid PGI signs still indicate the actual number of available spaces and therefore may be encouraging more drivers to divert to alternative car parks.

Placing PGI signs close to the car park entrances provides slightly greater savings in travel times than placing them at major decision points on the approach to the city centre. This is consistent with the findings of Axhausen, Polak, Boltze and Puzicha (1994) ${ }^{1}$ who noted that some drivers tend to turn to parking guidance information when their initial parking strategy fails. The best performing PGI sign type and location strategy however was the intensive covering of Hybrid PGI signs with an additional layer of Hierarchical signs on the approaches to the city centre. As could be expected, the results show that increasing the number of signs is subject to diminishing marginal returns.

Overall, the total travel time savings (that can be achieved by installing and operating a PGI system) were found to be small. Results from the simulated scenarios indicate that savings were frequently less than $0.5 \%$, although this value was increased as the demand for parking increases, which is consistent with the findings of both Axhausen, Polak, Boltze and Puzicha (1994) $)^{1}$ and Kurauchi, Iida and Yoshiya (1998) ${ }^{5}$. When demand is sufficiently high however that all car parks become full simultaneously, then parking guidance information may have little benefit. This small percentage saving in travel times is unlikely to generate extra journeys within the network.

Examining results on the savings that can be achieved for each section of the journey individually (driving, queuing, searching and walking) suggests that the greatest proportionate savings are obtained in queuing time (up to $7 \%$ overall). Comparison of the car park occupancy profiles for scenarios with and without parking guidance information shows that the amount of time when car parks are $95 \%$ or more full was reduced when the parking guidance information was available (see Figure 5) which is similar to the effect observed by Andrews and Hillen (1980) ${ }^{3}$. It appears that parking guidance information has the effect of spreading the demand more evenly across car parks, away from both the most utilised car parks and from little utilised car parks and towards moderately used car parks. The second of these effects is far smaller in magnitude and is a result of drivers being informed that there are spaces in car parks where they would not have expected there to be.

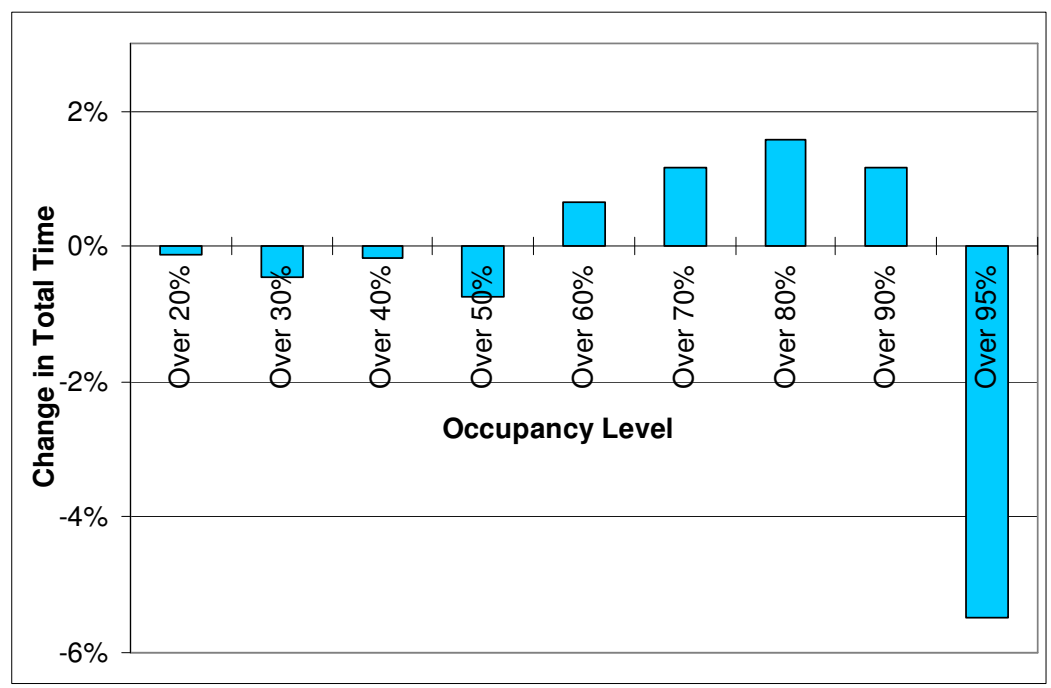

Figure 5 Changes in Car Park Occupancy Levels

The effects of parking guidance information on drivers who are unfamiliar with the network are mainly consequences of changes made by the much greater number of familiar drivers. Increasing the proportion of familiar drivers utilising the information resulted in increased savings in travel time when parking demand was high. This confirms the findings of Kurauchi, Iida and Yoshiya $(1998)^{5}$ that benefit is increased when the number of drivers who are informed of space availability is increased, especially when there is limited spare capacity in the system. This may provide evidence to justify advertising campaigns to accompany system installation.

Comparing the 'intensive coverage of PGI signs' scenarios with the equivalent 'no PGI signs' scenarios suggests that the number of drivers arriving at a car park entrance and opting not to park can be reduced by up to $0.7 \%$. A consequence of this reduction in circulating traffic is a small decrease in general congestion levels within the network, producing savings in travel time for all drivers, including PNR drivers. 
This is a post-peer-review, pre-copyedit version of an article published in the Journal of the Operational Research Society. The definitive publisher-authenticated versionWaterson, B.J., Hounsell, N.B. and Chatterjee, K. (2001) Quantifying the potential savings in travel time resulting from parking guidance systems - a simulation case study. Journal of the Operational Research Society, 52, (10), 1067-1077. (doi:10.1057/palgrave.jors.2601207) - is available online at:

http://www.palgrave-journals.com/jors/journal/v52/n10/abs/2601207a.html

The impact of PGI information when the capacity of a car park is reduced by $50 \%$ without warning depends on both the size of the car park concerned and the usual demand to use it. Parking guidance information was most beneficial when the capacity reduction affected a car park which was normally used by a substantial number of vehicles. However, when the capacity reduction affected so many vehicles that it led to no spare capacity being available in the entire system then PGI signs were unable to help significantly in mitigating the impacts of the capacity reduction on travel time.

\section{Conclusions}

This study set out to develop a model for parking choice to quantify the effectiveness of parking guidance and information signs in reducing the travel times of drivers attempting to use public car parks. Although benefits were discovered, their magnitude was small, with reductions in total travel time for all drivers in the network typically in the range $0.1 \%$ to $1.0 \%$ corresponding to economic benefits of up to $£ 500$ per day for the test network of approximately forty thousand vehicles.

Although this research has confirmed the effects of parking guidance information observed in earlier studies, it appears that on a network-wide level the impact of such systems on average travel time is severely limited. The conclusion must be that the cost of installing and operating a parking guidance and information system is unlikely to be justifiable purely on the grounds of reduced travel times.

\section{References}

1. Axhausen KW, Polak JW, Boltze M and Puzicha J (1994) Effectiveness of the Parking Guidance Information system in Frankfurt am Main. Traffic Engineering and Control 35: 304-309.

2. Polak JW, Hilton IC, Axhausen KW and Young W (1990) Parking guidance and information systems: performance and capability. Traffic Engineering and Control 31: 519-524.

3. Rayman N and Stannett A (1981) Compact urban traffic control car park information system. Traffic Engineering and Control 22: 411-417.

4. Wright DA and Withill RA (1992) Variable message signing : measurement of effect. Proceedings of the Sixth IEE International Conference on Road Traffic Monitoring and Control. London, UK, pp190-194.

5. Kurauchi F, Iida Y and Yoshiya Y (1998). Dynamic traffic simulation model for evaluating parking guidance and information system. Presented at 3rd HKSTS. 1998, Hong Kong.

6. Waterson BJ, Chatterjee K and Hounsell NB (1999) Simulating the effectiveness of parking guidance systems. Presented at the $41^{\text {st }}$ annual conference of the Operational Research Society. September 1999, Edinburgh, UK.

7. Hunt PB, Robertson DI, Bretherton RD and Winton RI (1981) SCOOT - A traffic responsive method of coordinating signals., Transport Research Laboratory Report LR1014.

8. EUROSCOPE (1999) Evaluation results and comparative assessment. Project EUROSCOPE (TR1023) Deliverable 19, Part II.

9. Bonsall P, Palmer I and Balmforth P (1998) PARKIT - a simulated world for parking choice research. Presented at the $8^{\text {th }}$ World Conference on Transport Research. July 1998, Antwerp, Belgium.

10. Bonsall PW and Palmer IA (2001) Behavioural modelling of parking behaviour using data from a parking choice simulator. To be presented at the World Conference on Transport Research. 2001, Seoul.

11. McDonald M, Hounsell NB and Njoze SR (1995) Strategies for route guidance systems taking account of driver response. Proceedings of the 1995 Vehicle Navigation and Information Systems Conference. IEEE, USA, pp 328-333.

12. Taylor NB (1990) CONTRAM 5: an enhanced traffic assignment model. Transport Research Laboratory Report RR 249.

13. Bifulco GN (1993) A stochastic user equilibrium assignment model for the evaluation of parking policies. EJOR $71: 269-287$.

14. Polak JW, Axhausen KW, Jones PM, Cook A and Wofinden D (1993) Modelling Parking Search Behaviour in Central and Inner London. Report 756 Transport Studies Unit, University of Oxford.

15. Design Manual for Roads and Bridges, Volume 13 Section 2 : Highways Economics Note No.2. (1997).

Acknowledgements- The authors wish to thank the Engineering and Physical Sciences Research Council (EPSRC) for their support of this research, Peter Bonsall and Ian Palmer of the Institute for Transport Studies, University of Leeds and John Polak of the Centre for Transport Studies, University of London for their work in this study and the ROMANSE centre, Southampton for calibration data.

*Correspondence: B.J.Waterson, Transportation Research Group, Department of Civil and Environmental Engineering, University of Southampton, Highfield, Southampton SO17 1BJ, UK. 